\title{
THE POSSIBLE MACROECONOMIC IMPACT ON THE UK OF AN INFLUENZA PANDEMIC
}

\author{
MARCUS R. KEOGH-BROWN ${ }^{\mathrm{a}}$, SIMON WREN-LEWIS ${ }^{\mathrm{b}}$, W. JOHN EDMUNDS ${ }^{\mathrm{a}}$, PHILIPPE BEUTELS \\ and RICHARD D. SMITH ${ }^{\mathrm{a}, *}$ \\ ${ }^{a}$ Department of Public Health and Policy, London School of Hygiene and Tropical Medicine, London, UK \\ ${ }^{\mathrm{b}}$ Department of Economics, University of Oxford, London, UK \\ ${ }^{\mathrm{c}}$ Department of Epidemiology and Social Medicine, University of Antwerp, Antwerpen, Belgium
}

\begin{abstract}
SUMMARY
Little is known about the possible impact of an influenza pandemic on a nation's economy. We applied the UK macroeconomic model 'COMPACT' to epidemiological data on previous UK influenza pandemics, and extrapolated a sensitivity analysis to cover more extreme disease scenarios. Analysis suggests that the economic impact of a repeat of the 1957 or 1968 pandemics, allowing for school closures, would be short-lived, constituting a loss of 3.35 and $0.58 \%$ of GDP in the first pandemic quarter and year, respectively. A more severe scenario (with more than $1 \%$ of the population dying) could yield impacts of 21 and $4.5 \%$, respectively. The economic shockwave would be gravest when absenteeism (through school closures) increases beyond a few weeks, creating policy repercussions for influenza pandemic planning as the most severe economic impact is due to policies to contain the pandemic rather than the pandemic itself.

Accounting for changes in consumption patterns made in an attempt to avoid infection worsens the potential impact. Our mild disease scenario then shows first quarter/first year reductions in GDP of 9.5/2.5\%, compared with our severe scenario reductions of $29.5 / 6 \%$. These results clearly indicate the significance of behavioural change over disease parameters. Copyright (C) 2009 John Wiley \& Sons, Ltd.
\end{abstract}

Received 7 June 2007; Revised 13 August 2009; Accepted 22 August 2009

KEY WORDS: macroeconomic modelling; influenza; UK; cost

\section{INTRODUCTION}

Infectious disease outbreaks, such as Variant Creutzfeldt-Jakob disease, foot and mouth disease and severe acute respiratory syndrome (SARS), quickly capture professional and popular attention (Blanke et al., 2001; Garner et al., 2002; Thompson et al., 2002; Smith, 2006). More recently, bird flu (H5N1) and swine flu (H1N1) have prompted renewed concerns about a more serious influenza pandemic (Cooper and Coxe, 2005). The focus of this attention tends to be on the health impact of such outbreaks, particularly mortality (Bartlett and Hayden, 2005). Although there is awareness that the economic impact may potentially be large, the details of this are unclear. For instance, the economic impact of the SARS outbreak of 2003 was far greater in sectors other than healthcare (Keogh-Brown and Smith, 2008); the bulk of the estimated US\$30bn to US\$100bn falling on the tourism and travel sectors (Fan, 2003; Lee and McKibbin, 2003; Smith and Sommers, 2003; Knapp et al., 2004). Overall, there is little empirical work on the likely impact of an influenza pandemic on a nation's economy or how this might vary with different potential epidemiological features.

\footnotetext{
*Correspondence to: Department of Public Health \& Policy, London School of Hygiene and Tropical Medicine, Keppel Street, London WC1E 7HT, UK. E-mail: Richard.Smith@1shtm.ac.uk
} 
This paper seeks to address these issues through the application of an established macroeconomic model of the UK economy, using epidemiological data from past influenza pandemics, in order to estimate the possible economic impact on the UK economy if such a pandemic were to occur today. Treating the mild disease scenario (based on the latter two pandemics of the 20th century) as a base case, we then construct further disease scenarios by increasing the severity of the disease parameters to investigate what the economic effect of a more severe influenza pandemic might be.

\section{METHODS}

\subsection{COMPACT model}

COMPACT is a quarterly macroeconomic model of the UK, developed with support from the UK's Economic and Social Research Council. Its structure reflects current macroeconomic theory (such as a consumption function derived explicitly from intertemporal optimisation), and most of its parameters are econometrically estimated rather than calibrated. It has been used to address a number of macroeconomic issues such as the impact of fiscal policy on the exchange rate (Wren-Lewis et al., 1996). The model uses aggregate variables and is therefore ideally suited to modelling an economic shock based on changes to the entire working population, such as those produced by pandemic influenza.

COMPACT has two specific advantages for our purposes. First, it is a structural econometric model, making the identification and application of specific shocks much more tractable than in a model based on a vector autoregressive (VAR) approach. Most policy making institutions use structural models for their core modelling purposes (see Holder, 2004 for example). (For a discussion of these difficulties, and a novel attempt to apply structural shocks to a VAR model of the UK, see Jacobs and Wallis (2005), who apply their technique to the model of (Garratt et al., 2003), and compare their results with COMPACT.) Second, it is based on recent, 'microfounded' macroeconomic theory, and therefore shares many of the desirable characteristics of Computable General Equilibrium models (Smith et al., 2005). For example, consumption decisions derived from intertemporal optimisation mean that most consumers are likely to smooth the impact of any transitory loss in income that might result from a short-lived pandemic, although COMPACT does allow for an estimated proportion of consumers (around 15\%) where credit constraints may prevent such smoothing. In addition, the model includes a labour market where the impact of changes in the working population on wages of the type identified by (Garrett, 2008) will be present. Finally, COMPACT is estimated and solved under the assumption that expectations are rational, which reduces the impact of the 'Lucas critique' (Lucas, 1976) on its results.

COMPACT is a New Keynesian model, where nominal rigidities exist in wage and price setting, but agents optimise in the face of these constraints in a forward-looking way. Monetary policy is set according to an interest rate reaction function that moves real interest rates gradually in response to movements in inflation away from an inflation target. Fiscal policy adjusts income taxes to ensure that the ratio of government debt to GDP returns gradually to its preshock level. A complete description of the model is available elsewhere (Darby et al., 1999).

\subsection{Influenza pandemic scenarios}

There were three influenza pandemics of the 20th century: 1918, 1957 and 1968/1969. Each was characterised by the rapid global spread of influenza. In the UK (and many other countries), there were three distinct waves of the 1918 pandemic, each lasting 10-15 weeks (Ministry of Health, 1920), with the largest occurring in the autumn of 1918. The 1957 pandemic occurred in the autumn of that year and comprised a single wave of about 15 weeks (Ministry of Health, 1960). The 1968/1969 pandemic affected the UK somewhat late in the normal influenza season resulting in a small first wave in March 1969, and a main wave in midwinter of 1969/1970 (Cooper et al., 2006). 
Clinical Attack Rates (CAR), representing the proportion of the population experiencing influenza like symptoms, during the 1918 pandemic were published by the Ministry of Health. When combined with data from block census enumerations made in a number of English cities a cumulative attack rate of $25 \%$ is indicated. Higher clinical attack rates were recorded for the 1957 (e.g. $>30 \%$ (Woodall and Rowse, 1957)) and 1968/1969 (>45\% (Davis et al., 1970)) pandemics. In these latter two pandemics the clinical attack rates appear to have been highest in children, whereas the highest recorded incidence in the 1918 pandemic was in young adults (Ministry of Health, 1920).

The Case Fatality Rate (CFR) of the disease gives the proportion of infected individuals who die from influenza. Although the morbidity patterns appeared broadly similar for the three pandemics, there were dramatic differences in the mortality patterns. By fitting a low-frequency sine-wave (Serfling, 1963) to the age-specific weekly mortality data around the time of the pandemics it is possible to estimate the excess deaths by age associated with the new strains of influenza. Such analyses suggest that the pandemic of 1918 resulted in about 201000 excess deaths in England and Wales (out of a population of about 40 million), whereas the 1957 and 1968/1969 pandemics 'only' resulted in about 18000 and 46000 deaths, respectively (Edmunds et al., 2007; in preparation). In addition, these latter two epidemics largely resulted in deaths in the elderly (in 1969 an estimated $86 \%$ of deaths occurred in those over 65 years of age), whereas in 1918 deaths were more evenly spread across all age groups (indeed the death rates were highest in those aged 25-35 years of age) (Edmunds et al., 2007; in preparation).

Changes in societal behaviour in the modern world, together with changes in public health policy mean that the economic impact of a recurrence of the 1918 pandemic would be very different in today's economy. However, by using the more recent pandemics as a base case for disease scenarios and extrapolating beyond the severity of more serious pandemics, such as 1918, it is possible to generate some useful hypotheses and stimulate thinking on the potential economic impact of infectious disease outbreaks (Beutels et al., 2008). While past pandemics cannot be used as a definitive guide in predicting the future, historical data provide a useful first attempt to illustrate the potential severity of an otherwise unpredictable disease.

Thus, for the purposes of this study, the base case assumes a CAR of $35 \%$ as was the case for the 1957 and 1968 influenza pandemics. The epidemic is assumed to last one quarter, which was also true of the other 20th century influenza pandemics, and also of SARS, and as COMPACT is a quarterly model this is the most sensible timescale to use. The duration of illness for future strains of influenza is unknown; however, it is reasonable to assume that the illness duration of pandemic influenza will be at least as long as for seasonal influenza (which is 5 days (Postma et al., 2005)) and longer for more severe pandemics. Those affected are therefore assumed to take an average of 5 days of work. To allow for increased severity, we also permit a value of $50 \%$ for the CAR for some scenarios, which would result in a further increase in deaths (as the proportion who die is simply the CAR*CFR). This upper bound on CAR is based on data from (Davis et al., 1970). The most severe scenarios have high CAR and CFR and are assumed on average to result in 7 days off work per infected individual.

Table I summarises the epidemiological scenarios modelled using scenarios, which vary the disease parameters. Table II gives the numbers of deaths by age that would be expected based on past influenza pandemics using the current population structure of the UK. ${ }^{1}$

\subsection{The 'Shock' - impact on the working population}

The shock to the working population is expressed as deaths, direct absenteeism (caused by infection) and indirect absenteeism (caused by school closure and 'prophylactic' avoidance of work).

${ }^{1}$ Unpublished analysis by the Health Protection Agency. 
Table I. Morbidity and mortality estimates

\begin{tabular}{|c|c|c|c|c|c|c|}
\hline & $\begin{array}{l}\text { Case fatality } \\
\text { ratio } \% \\
\text { (working } \\
\text { population) }\end{array}$ & $\begin{array}{l}\text { Clinical attack } \\
\text { rate } \% \\
\text { (working } \\
\text { population) }\end{array}$ & $\begin{array}{c}\text { Working population } \\
\text { mortality } \\
\text { rate } \%\end{array}$ & $\begin{array}{l}\text { Days } \\
\text { lost }\end{array}$ & $\begin{array}{l}\text { School } \\
\text { closure } \\
\text { (weeks) }\end{array}$ & $\begin{array}{l}\text { Prophylactic } \\
\text { absenteeism } \\
\text { (weeks) }\end{array}$ \\
\hline Base & 0.04 & 35 & 0.01 & 5 & 0 & 0 \\
\hline Increased CFR & 2.5 & 35 & 0.88 & 5 & 0 & 0 \\
\hline Increased CAR & 0.04 & 50 & 0.02 & 5 & 0 & 0 \\
\hline Base with 4 weeks SC & 0.04 & 35 & 0.01 & 5 & 4 & 0 \\
\hline Base with quarter SC & 0.04 & 35 & 0.01 & 5 & 13 & 0 \\
\hline Base with mild PA & 0.04 & 35 & 0.01 & 5 & 0 & 1 \\
\hline Base with PA & 0.04 & 35 & 0.01 & 5 & 0 & 4 \\
\hline Base with quarter SC and mild PA & 0.04 & 35 & 0.01 & 5 & 13 & 1 \\
\hline Base with quarter SC and PA & 0.04 & 35 & 0.01 & 5 & 13 & 4 \\
\hline School closure with increased CFR & 2.5 & 35 & 0.88 & 5 & 4 & 0 \\
\hline School closure with increased CAR & 0.04 & 50 & 0.02 & 5 & 4 & 0 \\
\hline School closure with mild PA & 0.04 & 35 & 0.01 & 5 & 4 & 1 \\
\hline School closure with PA & 0.04 & 35 & 0.01 & 5 & 4 & 4 \\
\hline Severe disease (no SC or PA) & 2.5 & 50 & 1.25 & 7 & 0 & 0 \\
\hline Severe disease with SC & 2.5 & 50 & 1.25 & 7 & 4 & 0 \\
\hline Severe disease with quarter SC & 2.5 & 50 & 1.25 & 7 & 13 & 0 \\
\hline Severe disease with mild PA & 2.5 & 50 & 1.25 & 7 & 0 & 1 \\
\hline Severe disease with severe PA & 2.5 & 50 & 1.25 & 7 & 0 & 4 \\
\hline $\begin{array}{l}\text { Severe disease with quarter SC and } \\
\text { severe PA }\end{array}$ & 2.5 & 50 & 1.25 & 7 & 4 & 1 \\
\hline $\begin{array}{l}\text { Severe disease with quarter SC and } \\
\text { severe PA }\end{array}$ & 2.5 & 50 & 1.25 & 7 & 13 & 4 \\
\hline
\end{tabular}

Table II. Deaths by age group

\begin{tabular}{lcc}
\hline Age (years) & Deaths in severe (1918-like) scenario & Deaths in $1957 / 1969$ (base) scenario \\
\hline$<15$ & 55400 & 300 \\
$15-24$ & 39200 & 200 \\
$25-34$ & 40700 & 200 \\
$35-4$ & 46800 & 300 \\
$45-54$ & 38800 & 3200 \\
$55-64$ & 35200 & 2900 \\
$65-74$ & 25600 & 18200 \\
$75+$ & 23400 & 16600 \\
Total & 305100 & 41900 \\
\hline
\end{tabular}

2.3.1. Deaths. Deaths apply a permanent shock to the working population and, as presented in Table I, are estimated as the product of the CAR and the CFR for the working-age population. The CFR for the mild (base case) scenario is calculated from the average of age-specific estimates for 1957 and 1969 (0.04\%; Edmunds et al., 2007). For the more severe scenario, we use a $2.5 \%$ CFR (similar to that observed in 1918).

2.3.2. Direct absenteeism. The duration of illness for influenza is quite short and people feel unwell for a short while afterwards (Postma et al., 2005). The CAR of 35\% combined with the assumed duration of absence (Table I) means that, for the quarter affected by the pandemic, $3 \%$ (5 days) or $4 \%$ ( 7 days) of working days will be lost due to direct absenteeism in the base and severe scenarios, respectively.

2.3.3. Indirect absenteeism. During an outbreak of pandemic influenza it is probable that schools will be closed for a few weeks to reduce disease spread, but as the duration of this closure is unknown, we 
assume three scenarios. The first involves no closure of schools during the pandemic, the second involves closing schools for 4 weeks at the height of the pandemic and the third involves closure for the entire pandemic (13 weeks). Analysis of the Labour Force Survey (2005) suggests that there are a total of 25245000 individuals aged 16-64 who are in paid employment. Of these 3900000 are women who are either the head of the household or the spouse of, or cohabiting with, the head of the household and have dependent children in the household $<16$ years of age. That is, $15.5 \%$ of the workforce comprises women who are probably responsible for dependent children (Sadique et al., 2008). Assuming school closure will last 4 weeks, an average of $4.8 \%{ }^{2}$ of working days will be lost in the quarter of the pandemic due to school closure. In the event of schools closing for the duration of the pandemic this figure would increase to $15.5 \% .^{3}$

2.3.4. Prophylactic absenteeism. A further possibility in the event of an influenza pandemic is that of prophylactic absenteeism where healthy workers remove themselves from their workplace in an attempt to avoid infection. Such absenteeism is limited in its duration as unjustified absence will not be tolerated by most employers and therefore prophylactic absentees would be forced to take annual leave (as longer term sick-leave usually requires General Practitioner authorisation and these individuals are, by definition, not sick). It is therefore reasonable to assume that such absenteeism is likely to last 4 weeks or less.

Prophylactic absenteeism in the event of a major pandemic was surveyed in Sadique et al. (2007). The results of this survey state that $34 \%$ of workers would take prophylactic absenteeism in the event of an influenza pandemic, of which $3.75 \%$ were women who had children at school and would therefore overlap with the school closure absenteeism. However, the remaining $30 \%$ represent the additional shock due to prophylactic absenteeism. ${ }^{4}$ It should be highlighted that there is some uncertainty as to whether individuals who state an intention to take prophylactic absenteeism would, in reality, carry out this intention, so this shock could be seen as a worst case scenario.

2.3.5. Mitigating factors on production. In reality the impact on production is likely to be less than the shock induced by summing our estimates for direct and indirect absenteeism. Substitution among the workforce, where those who are not ill work additional hours, will reduce the impact of absenteeism, though at some (friction) cost to the firm (Brouwer and Koopmanschap, 2005). Equally, firms or plants in parts of the UK, which are less affected at the time of the pandemic will be able to make up for the production lost elsewhere, although again at some cost to particular firms. Another possibility is that firms may reduce the impact of a lower labour input on production by substituting capital (in COMPACT the production technology has a vintage structure, so the scope for direct substitution is very small, but firms will be able to use their remaining workforce on the more productive machines). Finally, to the extent that firms hold stocks of final goods (either directly or through wholesalers and retailers), they may be able to make good some of the decline in stocks caused by lost production within the quarter of the pandemic. While it is unlikely that completely making good lost stocks in this way would be optimal, the extent of this kind of substitution is likely to be greater in the base scenario compared with the more severe pandemic scenarios.

2.3.6. Consumption. Those who are ill are likely to consume fewer goods, such as food and alcohol, and services, such as travel (Sadique et al., 2007), but as these consumption effects are small and would only last for the duration of illness ( 5 or 7 days) they have not been modelled. However, there is some

\footnotetext{
${ }^{2}$ Since 4 weeks of school closure results in absence of $15.5 \%$ of the workforce for $30.1 \%$ of the quarter: $0.301 \times 15.5=4.8$. ${ }^{3}$ Since closing schools for the duration of the pandemic results in absenteeism by $15.5 \%$ of the workforce for the entire quarter. ${ }^{4}$ It is interesting also to note that, in the absence of this survey data and applying the assumption made for the whole workforce to the prophylactic absentees, $15.5 \%$ of the prophylactic absentees would be assumed to overlap with the school closure individuals, which yields a $29 \%$ prophylactic absenteeism shock, which is very similar to the survey results.
} 
evidence to suggest that there will be declines in consumption by those who are seeking to avoid illness. However, as any such consumption shock is uncertain and would depend on unpredictable features of the pandemic we have considered just two scenarios with consumption impacts.

In the survey conducted in Sadique et al. (2007) it was revealed that approximately $75 \%$ of people would avoid making purchases in the areas of leisure, transport, furnishings, clothes, cars and tourism during a pandemic. The losses to transport and leisure are not likely to be made up after the pandemic as those who avoid public transport, watching sports events, etc. are unlikely to increase consumption of those items after the pandemic. Moreover, consumption losses for furnishings, clothes, cars and tourism are more likely to be deferred during the pandemic rather than lost altogether. However, this precautionary behaviour is only applicable to those who are well and have not had flu, as those who have been infected cannot be re-infected and so are likely to behave normally. We therefore need to apply our consumption shocks to the proportion of those who do not get flu (1-CAR) and apply the consumption shock to those who are infected for the period before their infection. For convenience we assume that individuals are likely to be infected, on average, halfway through the pandemic and therefore apply the consumption shocks to the proportion of infected individuals (CAR) for half of the pandemic.

For utilisation in the COMPACT model we translate our consumption shocks into the following sectors:

- Food, drink, alcohol and tobacco

- Clothing and footwear

- Housing, heating, etc.

- Goods and services (furniture, etc.)

- Transport

- Recreation and culture

- Restaurants, hotels and net tourism

- Miscellaneous (incl health, communication education)

We assume no significant effect on food or housing or to the miscellaneous category of items. However, as some proportion of clothing and footwear can be bought alongside food, etc., we assume a reduction of $50 \%$ in purchases in this category as a result of precautionary behaviour by the well, all of which is made up for in subsequent quarters. Goods and services, in contrast, usually involve specialised purchases and we therefore allow an $80 \%$ postponement in this category.

Approximately one-third of transport involves car purchase, and the remainder is the use of services and car use. We assume complete postponement of car purchase. Some proportion of car and service use is likely to continue for travel to work and we therefore assume a reduction of $50 \%$, none of which is recouped in subsequent quarters.

Just under $30 \%$ of recreation and culture involves the purchase of durables. A similar share is 'games and pets', and again sport and culture, with a residual 10\% being newspapers and books. For simplicity, we assume the proportion due to sport and culture is permanently lost, and that the durables element is postponed, with no effect on the remainder.

Finally, we assume that all of spending on restaurants, etc. is lost.

The total bounce back ${ }^{5}$ will be around $18 \%$ of consumption (i.e. just over $5 \%$ of a quarter's consumption is lost forever). We assume that a small part of this $18 \%$ bounce back takes place a year after the pandemic (e.g. annual holidays), and that the remainder occurs mainly in the subsequent quarter.

\footnotetext{
${ }^{5}$ After a shock to the economy has passed, losses can be partially or completely recouped in subsequent periods, we refer to this as 'bounce back'.
} 
Table III. Breakdown of consumption assumptions (2006 data)

\begin{tabular}{lccc}
\hline Category & $\begin{array}{c}\text { \% share of } \\
\text { average person }\end{array}$ & $\begin{array}{c}\text { Permanent loss of precautionary } \\
\text { agents as o of their total }\end{array}$ & $\begin{array}{c}\text { Delay by precautionary agents } \\
\text { as of their total }\end{array}$ \\
\hline Food, drink, alcohol and tobacco & 12.51 & 0 & 0 \\
Clothing and footwear & 5.81 & 0 & 2.91 \\
Housing, heating, etc. & 19.98 & 0 & 0 \\
Goods and services (furniture, etc.) & 5.7 & 0 & 4.56 \\
Transport & 14.64 & 4.83 & 4.98 \\
Recreation and culture & 12.3 & 3.69 & 3.69 \\
Restaurants, hotels and net tourism & 13.07 & 0 & 13.07 \\
Misc (incl health, communication education) & 15.99 & 0 & 0 \\
Total & 100 & 8.52 & 29.21 \\
\hline
\end{tabular}

COMPACT has only an aggregate consumption equation, so these sectoral figures are translated into aggregate shocks that are applied in the model, and are tabulated in Table III.

Note that the assertions in this section and the model assumptions we make on their basis, concur with consumption patterns observed during and shortly after the 2003 SARS outbreak in Beijing (Beutels et al., 2009).

\subsection{Other influences}

Investment involving construction is likely to be hit directly by the reduction in hours worked. Investment in plant and machinery may be postponed in the very short term as a result of the uncertainty generated by the pandemic. Overall investment within the model is assumed to fall by varying amounts proportional to the number of days lost in each scenario.

Government consumption may see small influences from the school closure and increased health costs, but these are likely to be small as the health service operates at close to maximum capacity, so the extra cases largely displace routine health care (Beutels et al., 2008). For simplicity we assume no net effect. There may be a long-term gross effect caused by those patients whose treatment was postponed. These costs may be captured by a detailed dynamic sectoral model, but our assumption is reasonable based on the nonsectoral nature of COMPACT and the timescale chosen.

As noted above, another impact of the pandemic will be to increase firms' costs. In most cases, any reduction in output caused by absenteeism will not be reflected in a fall in the wage bill (as most workers will still be paid while ill), so costs per unit of output will rise. As noted earlier, the impact on production is likely to be less than the shock induced by summing our estimates for direct and indirect absenteeism; however, the impact on firms costs is proportional to the number of days lost and additional overtime that must be paid for.

For simplicity we also assume that the overseas output and demand reductions occur at a similar time to the UK. A recent analysis (McKibbin and Sidorenko, 2006) broadly suggests that the impact would be less in the USA, but larger in more open economies. (We have made no allowance for any impact on the value of Sterling, as it seems reasonable that any concern about the currencies of 'exposed' countries would have little impact on Sterling relative to the currencies of our major competitors). It is therefore reasonable to suggest that the impact of the pandemic overseas would be similar to the UK impact.

\section{RESULTS}

Results for all scenarios except those with the additional consumption shock are tabulated in Table IV. All results are calculated as deviations from a no-pandemic base. 
Table IV. Percentage impacts on GDP, consumption and inflation

\begin{tabular}{|c|c|c|c|c|}
\hline & GDPQ1 & Consumption Q1 & GDP Y1 & Inflation Y1 \\
\hline Base & -1.24 & -0.4 & -0.22 & 0.17 \\
\hline Increased CFR & -3.22 & -2.62 & -1.03 & 0.19 \\
\hline Increased CAR & -2.20 & -0.68 & -0.37 & 0.26 \\
\hline Base with 4 weeks SC & -3.35 & -1.07 & -0.58 & 0.46 \\
\hline Base with quarter SC & -8.1 & -2.56 & -1.44 & 1.07 \\
\hline Base with mild PA & -2.43 & -0.78 & -0.42 & 0.34 \\
\hline Base with PA & -6.01 & -1.92 & -1.06 & 0.82 \\
\hline Base with quarter SC and mild PA & -9.14 & -2.89 & -1.64 & 1.19 \\
\hline Base with quarter SC and PA & -12.27 & -3.84 & -2.23 & 1.54 \\
\hline School closure with increased CFR & -5.83 & -3.4 & -1.47 & 0.49 \\
\hline School closure with increased CAR & -4.8 & -1.47 & -0.81 & 0.57 \\
\hline School closure with mild PA & -4.41 & -1.41 & -0.77 & 0.61 \\
\hline School closure with PA & -7.58 & -2.41 & -1.35 & 1.01 \\
\hline Severe disease (no SC or PA) & -5.49 & -3.16 & -1.55 & 0.39 \\
\hline Severe disease with SC & -8.51 & -4.03 & -2.06 & 0.68 \\
\hline Severe disease with quarter SC & -15.14 & -5.9 & -3.24 & 1.22 \\
\hline Severe disease with mild PA & -7.17 & -3.65 & -1.84 & 0.56 \\
\hline Severe disease with severe PA & -12.33 & -5.11 & -2.75 & 1 \\
\hline Severe disease with quarter SC and severe PA & -9.96 & -4.44 & -2.31 & 0.8 \\
\hline Severe disease with quarter SC and severe PA & -21.25 & -7.61 & -4.45 & 1.64 \\
\hline
\end{tabular}

\subsection{Disease only scenarios}

The most basic illness scenario (the first column of Table IV, labelled 'base case') has GDP falling by $1.24 \%$ in the quarter of the attack, compared with the level of GDP that would have occurred in the absence of a pandemic. In subsequent quarters GDP is slightly higher than it would have been without the attack, as firms replenish stocks and investment recovers slightly. For the year as a whole, GDP is reduced by just $0.22 \%$. The fall in consumption is small, reflecting in part the impact of lower GDP on incomes, and the impact of higher costs on inflation is also modest.

When increasing the CFR from the base scenario, the impact on GDP is more than doubled to $3.22 \%$. The GDP loss for the year is increased by a factor of almost five to $1.03 \%$, although inflation is little changed. The higher mortality of this scenario has a clear impact on the outcome as this scenario differs from the base case only in the extent of fatalities that result from the pandemic. The loss of nearly $1 \%$ in the working population will have a permanent impact on the supply of output, and a permanent reduction in consumption. The impact on investment is more drawn out than in the base case, although after a few quarters we see some recovery as capital is substituted for labour. Although firms' costs increase more in this scenario, because more working days are lost, the impact on inflation is hardly changed, because more depressed demand lowers profit margins.

Increasing the CAR from the base scenario also has a significant effect, although here the pattern in the base is retained. The GDP and consumption impacts for the first quarter are 2.2 and $0.68 \%$, respectively, and the GDP impact for the year is a $0.26 \%$ loss. This raises the number of days lost through illness. (We would get similar effects if we kept the CAR rate at 35\%, but instead raised the number of working days lost per ill person from five to seven.) Despite the larger fall in GDP, the impact of the pandemic in this scenario is short-lived, with some bounce back in GDP in subsequent quarters (not shown). The value for year 2 (the first pandemic-free year after the shock) is small but positive showing that the effect has dissipated.

\subsection{Base case disease with school closure scenarios}

Introducing school closure (the most likely policy option) to the base scenario causes a further decline in labour supply. Here working days are lost as an indirect result of the illness, as parents (in the main) 
stay at home to look after their children. Four weeks of school closure (at the height of the pandemic) generate a GDP loss of $3.35 \%$ for the first quarter and $0.58 \%$ for the first year. This is higher for the first quarter than the increased CFR and CAR scenarios, but falls to a lower level than the former at 1 year. Inflation, however, is affected more strongly than the previous scenarios with a $0.46 \%$ impact at year 1.

Closing schools for 13 weeks (the duration of the epidemic) increases the economic impact. First quarter GDP loss is up to $8.1 \%$, first year GDP loss is $1.44 \%$ and first quarter consumption declines by $2.56 \%$. Inflation also increases to $1.07 \%$ at 1 year.

\subsection{Base case disease with prophylactic absenteeism scenarios}

The introduction of prophylactic absenteeism, as with school closures, imposes an additional fall in labour supply. For the scenario where some individuals take 1 week of absence the loss to GDP is $2.43 \%$ in the first quarter and $0.42 \%$ at year 1 ; both of which are less serious impacts than in the previous nonbase scenarios. The impact on consumption is $0.78 \%$, and inflation rises to $0.34 \%$. Overall the addition of 1 week of prophylactic absenteeism is similar to the impact of increasing the CAR to $50 \%$.

For the scenario where individuals take 4 weeks of prophylactic absenteeism the impact on GDP is $6.01 \%$ in the first quarter and $1.06 \%$ at the first year. The impact at the first quarter is quite large but sharply declines to levels similar to those of increased CAR and CFR. Consumption falls by $1.92 \%$ at the first quarter, slightly less than in the increased CFR and 13-week school closure scenarios. Inflation rises by $0.82 \%$.

Overall, while prophylactic absenteeism has a notable short-term effect, this impact declines considerably by the first year. However, some inflation effects remain, which will impact in the longer term.

\subsection{Base case disease with school closure and prophylactic absenteeism}

In the scenarios where schools are closed and prophylactic absenteeism is taken, there is a large reduction in the labour supply and some fall in consumption. If 13 weeks of school closure is combined with 1 week of prophylactic absenteeism, the first quarter impacts on GDP and consumption are 9.14 and $2.89 \%$, respectively. However, by the first year, the GDP loss has declined to $1.64 \%$ while inflation suffers, rising by $1.19 \%$. This scenario represents the most serious impact so far and includes a longerterm effect on inflation.

In the more severe case where schools close throughout the pandemic and prophylactic absenteeism lasts for 4 weeks, the impacts are larger still: losses of $12.27 \%$ to GDP and $3.84 \%$ to consumption in the first quarter, and at 1 year the impact on GDP remains at 2.23\% loss. Inflation also increases by $1.54 \%$.

\subsection{School closure scenarios}

Under the assumption that schools will most likely be closed only for 4 weeks at the height of a pandemic, we consider scenarios based around that assumption. Combining 4 weeks of school closure with an increased CFR combines a larger number of deaths with the decreased labour supply resulting from school closure. This generates a loss of $5.83 \%$ to GDP in the first quarter and $1.47 \%$ at the first year. Consumption also falls by $3.4 \%$ in the first quarter and inflation rises by $0.49 \%$. The short-term effect of this scenario is slightly worse than that caused by increasing the CFR alone, but is not very different in the long-term.

Similarly, an increased CAR combined with school closure results in a short-term impact that is slightly worse than the scenario with an increased CFR alone, with first quarter impacts on GDP and 
consumption 4.8 and $1.47 \%$, respectively. After 1 year these impacts are $0.81 \%$ to GDP and $0.57 \%$ to inflation.

We also considered (not shown) combining 4 weeks of school closure with 1 and 4 weeks of prophylactic absenteeism. The impacts of these scenarios are similar to, though less serious than, the scenarios with 13 weeks of school closure combined with prophylactic absenteeism.

\subsection{Severe disease scenarios}

The severe disease scenarios represent increased CFR and CAR from the base case. We also consider the impact of school closure and prophylactic absenteeism in combination.

The estimated impact of the severe disease by itself (without school closure or prophylactic absenteeism) is a loss to GDP of $5.49 \%$ for the first quarter and $1.55 \%$ for the first year. Consumption in the first quarter falls by $3.16 \%$ and inflation rises by $0.39 \%$ for the first year. Although this scenario concerns disease only, the fall in consumption is greater than most of the previously considered scenarios because of the greater number of sicknesses and deaths. The GDP impact is similar to, though slightly more severe than, the base case disease scenario combined with 4 weeks of prophylactic absenteeism. The inflation impact is twice that of the base case disease scenario.

Introducing a 4 -week school closure policy in addition yields an $8.51 \%$ loss to GDP in the first quarter and $2.06 \%$ loss at the first year. Consumption falls by $4.03 \%$ in the first quarter and inflation rises by $0.68 \%$. This is the highest impact considered so far, with the exception of those with 13 -week school closures.

Combining 13 weeks of school closure with the severe disease scenario yields a fairly catastrophic first quarter GDP loss of $15.14 \%$. However, by the first year, this loss averages out to $3.24 \%$ and inflation rises by $1.22 \%$. During the first quarter consumption falls by $5.9 \%$.

One week's prophylactic absenteeism combined with severe disease yields GDP loss impacts of 7.17 and $1.84 \%$ at the first quarter and first year, respectively. Consumption falls by $3.65 \%$ in the first quarter and inflation rises by $0.56 \%$ in the first year. If the prophylactic absenteeism is increased to 4 weeks, the GDP losses for the first quarter and year rise to 12.33 and $2.75 \%$, respectively, consumption falls by $5.11 \%$ and inflation rises to $1 \%$.

Combining severe disease with a full quarter's school closure and 1 week of prophylactic absenteeism yields GDP losses of $9.96 \%$ at the first quarter and $2.31 \%$ at the first year. Consumption falls by $4.44 \%$ and inflation rises by $0.8 \%$.

The most extreme scenario combines severe disease with one quarter of school closure and 4 weeks of prophylactic absenteeism. This yields GDP impacts for the first quarter and first year of 21.25 and $4.45 \%$, respectively. Consumption falls by $7.61 \%$ and inflation rises by $1.64 \%$. This impact on GDP in the quarter of the pandemic is unprecedented. There is now significant persistence in both investment and consumption changes in subsequent quarters, in part because of the large increase in interest rates that would result in response to a rise of $1.6 \%$ in inflation, assuming that the authorities maintain their normal monetary policy rule. For the year as a whole, GDP is nearly $5 \%$ lower, a decline that is again unprecedented.

\subsection{Precautionary consumption scenarios}

Applying the precautionary consumption shocks mentioned earlier yields the results given in Table V. Introducing a consumption shock to the base disease scenario increases the GDP impact in the first quarter from 1.24 to $9.52 \%$ - more than seven times larger. For the most severe scenario, first quarter GDP impact increases from 21.25 to $29.45 \%$. The first year GDP impact for the base scenario is $2.52 \%-$ more than 10 times the original value and for the severe scenario it is $6.05 \%$ - an increase of nearly $2 \%$. Not surprisingly the consumption impacts are large. For the base scenario the consumption impact is multiplied by a factor greater than 50 yielding $24.92 \%$, for the severe scenario the consumption effect is 
Table V. Percentage impacts of disease scenarios with consumption shock

\begin{tabular}{lcc}
\hline & $\begin{array}{c}\text { Base with consumption } \\
\text { shock }\end{array}$ & $\begin{array}{c}\text { Severe disease with quarter SC and } \\
\text { severe PA and consumption shock }\end{array}$ \\
\hline GDP & & \\
Q1 & -9.52 & -29.45 \\
Q2 & 0.95 & 1.78 \\
Q3 & -1.11 & 1.74 \\
Y1 & -2.52 & -6.05 \\
Y2 & 0.59 & 1.04 \\
Consumption & -24.92 & -29.22 \\
Q1 & 9.9 & 8.50 \\
Q2 & -0.44 & -1.1 \\
Q3 & -3.95 & -5.73 \\
Y1 & 0.44 & -1.00 \\
Y2 & & \\
Investment & -0.95 & -16.18 \\
Q1 & 0.24 & 0.77 \\
Q2 & 0.09 & 0.02 \\
Q3 & -0.12 & -4.06 \\
Y1 & 0.1 & 0.43 \\
Y2 & & \\
Inflation & 0.59 & 2.8 \\
Q1 & -0.24 & 0.4 \\
Q2 & 0.09 & 0.62 \\
Q3 & 0.12 & 1.09 \\
Y1 & 0.05 & -0.24 \\
Y2 & & \\
\hline
\end{tabular}

more than three times larger at $29.22 \%$. The inflation impact for the base scenario is smaller than the original, at $0.12 \%$, as is the severe scenario inflation effect, at $1.09 \%$. This suggests a smaller long-term impact, but very large losses in the short term if our estimates of consumption decline are realised. The rise in inflation may seem surprising, as the negative demand shock is larger than the negative supply shock. However, while unemployment rises, and wage inflation falls a little as a result, this is more than counteracted by a sharp rise in costs, as firms retain labour (knowing the output reduction is temporary) well in excess of that required to produce the lower level of output. A small part of this increase in costs is passed on, but it is enough to raise inflation (although by an amount that is small relative to GDP movements).

Not only is the impact of the pandemic much greater with this scale of precautionary consumption losses, but its economic character also changes. In the simulations shown in Table IV, the economy essentially suffers a temporary supply shock, which reduces output but also raises costs. In the two simulations in Table V, we add an additional, and much larger, demand shock, as consumers reduce or postpone consumption. This negative demand shock adds to the decline in GDP, but it does not raise costs, and so the impact on inflation is mitigated.

\subsection{Comparison with existing studies}

There is little literature providing specific cost estimates of pandemic influenza. This is partly due to the scarcity of economic data from previous pandemics of 1918, 1957 and 1968-1969.

Brainerd and Siegler (2003) consider the economic effect of the 1918-1919 influenza pandemic, concluding significant positive correlation between the prime-age mortality of the influenza pandemic and business failure rates, that influenza contributed to the immediate post- WWI recessions, and that the total mortality rate from influenza and pneumonia in 1918 and 1919 is significantly and positively correlated to the growth in income per capita from 1919-1921 to 1930 across US states. This study 
highlights the long-term impact on GDP per capita but does not capture the short-term effects we estimate with the COMPACT model.

James and Sargent (2006) estimate the cost of the 1918 and 1957 influenza pandemics and the SARS outbreak to various countries including Canada and the US. The authors estimate the impact on various sectors and indicators of the economy without an economic model using individual morbidity, mortality and absenteeism impacts. GDP mortality and morbidity impacts for 1918 are estimated as -0.23 and $-0.28 \%$, respectively, and absenteeism by those caring for the sick is estimated to reduce GDP by between -0.03 and $-0.01 \%$. Their model of prophylactic absenteeism begins with an estimate of $35 \%$ absence but declines with time as more people become infected and then immune. Although we do not estimate absenteeism due to caring for sick relatives, many of our disease and absenteeism estimates are similar. The overall GDP estimates are quoted as with/without work avoidance absenteeism as: high absenteeism with no demand reallocation $-0.92 /-1.1 \%$, high absenteeism with full demand reallocation $-0.55 /-0.73 \%$, low absenteeism with no demand reallocation $-0.7 /-0.77 \%$, and low absenteeism with full demand reallocation $-0.34 /-0.4 \%$. The smaller impacts match the base disease estimates from our model, but the scenarios with high absenteeism yield smaller impacts than our scenarios with prophylactic absence and school closure. However, James and Sargent assume that school closure impacts would be very small, and as they have not used a structural economic model they could not solve simultaneously for the various shocks, as in our COMPACT model application.

Jonung and Roeger (2006) use the QUEST model to estimate the impact on the European economy of a mild and severe influenza pandemic in 2006. They assume a severe influenza scenario similar to the 1918 pandemic and to our 'increased CFR' scenario. Their mild scenario uses a CAR of $25 \%$ (less than our assumed CAR) and a CFR of $1.14 \%$ (larger than our CFR). The authors also consider an $80 \%$ reduction in demand for tourism and entertainment sectors including restaurants, bars and cinemas, which is very similar to our assumed consumption shock. Without the demand effect, the authors estimate a first year impact on GDP of $1.1 \%$ (similar to our 'increased CFR' estimate of $1.07 \%$ ). The demand effect increases this impact to $1.6 \%$, which is smaller than our consumption impact. The maximum estimate of direct pandemic effect is quoted as $4 \%$ of GDP, which is almost as large as our most severe scenario with consumption effects.

McKibbin and Sidorenko (2006) present a multi-country model, G-Cubed, with sectoral breakdown to estimate the macroeconomic cost of influenza. The authors consider various shocks: like our COMPACT application they use morbidity and mortality labour force shocks based on 1918, 1957 and 1968-1969 scenarios. They also apply sector specific shocks and shocks to demand similar to our consumption shocks. Overall, their UK impacts are estimated as mild (1968/1969-like) -0.72\%, moderate (1957-like) $-2.38 \%$, severe (1918-like) $-5.83 \%$ and ultra $-11.11 \%$. The mild impact is larger than our $-0.22 \%$ base result and the moderate impact is larger than all of our first year disease scenarios. Our introduction of school closure and prophylactic absence (which McKibben and Sidorenko do not model) cause our COMPACT estimates to approach the moderate G-cubed estimates but even our most severe disease scenario with quarter school closure and prophylactic absence does not reach the severe or ultra scenarios. Our estimate does not include the sectoral impacts, but assumes school closure.

Table VI. Overview of relevant GDP estimates from other studies

\begin{tabular}{lll}
\hline Country/region & \multicolumn{1}{c}{ Author } & \multicolumn{1}{c}{ Negative \% GDP impact range (min to max) } \\
\hline Canada & (James and Sargent, 2006) & $0.9-0.28$ (illness) \\
& & $0.34-0.92$ (total without workplace avoidance) \\
& & $0.4-1.1$ (total with workplace avoidance) \\
EU-25 & (Jonung and Roeger, 2006) & $1.1-1.6$ \\
UK & (McKibbin and Sidorenko, 2006) & $0.72-11.11$ \\
& This Study & $0.22-4.5$ (without consumption impact) \\
\end{tabular}


Overall, our study presents a model application that is not mirrored elsewhere. Table VI outlines the GDP impacts from other studies that might be compared with the results presented in this paper. The use of a structural model with scenarios representing disease together with prophylactic absence and school closure shocks is a useful contribution to the existing literature and while the COMPACT model does not study the sectoral impact, and the policy/behavioural shocks may not be fully realised in practice, it provides a helpful overall estimate of the potential impact on the UK economy.

\section{DISCUSSION}

If the pandemic does not modify consumption patterns of uninfected people, our base case (mild) pandemic scenario predicts GDP to fall by around $1.25 \%$ during the quarter of the pandemic. There is no significant impact in the quarter after the attack, and subsequently there is a small rebound in output. For the year as a whole, output is estimated to fall by $0.22 \%$. This result fits well with the figures for annual GDP for the late 1950s and 1960s (corresponding to the base pandemic scenario), which are plotted in Figures 1 and 2. These figures show no appreciable loss that might be attributed to the pandemic.

A feature of the simulations without any precautionary cuts in consumption is that the fall in consumption is relatively small, particularly when the number of deaths is also small. This reflects the important role of 'consumption smoothing' in this model: most consumers are able to cushion the impact of lower incomes in a single quarter due to the pandemic by borrowing or running down their

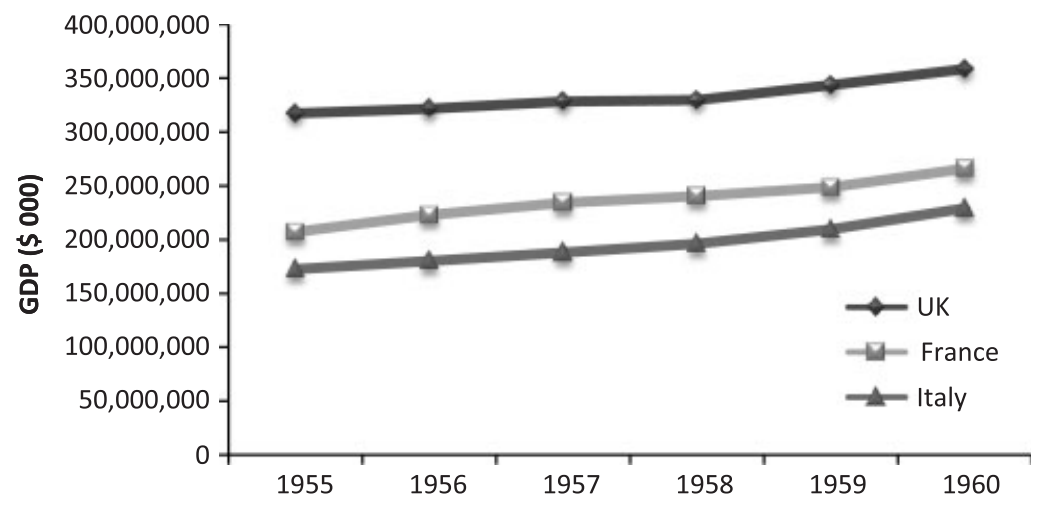

Figure 1. Annual GDP for 1955-1960

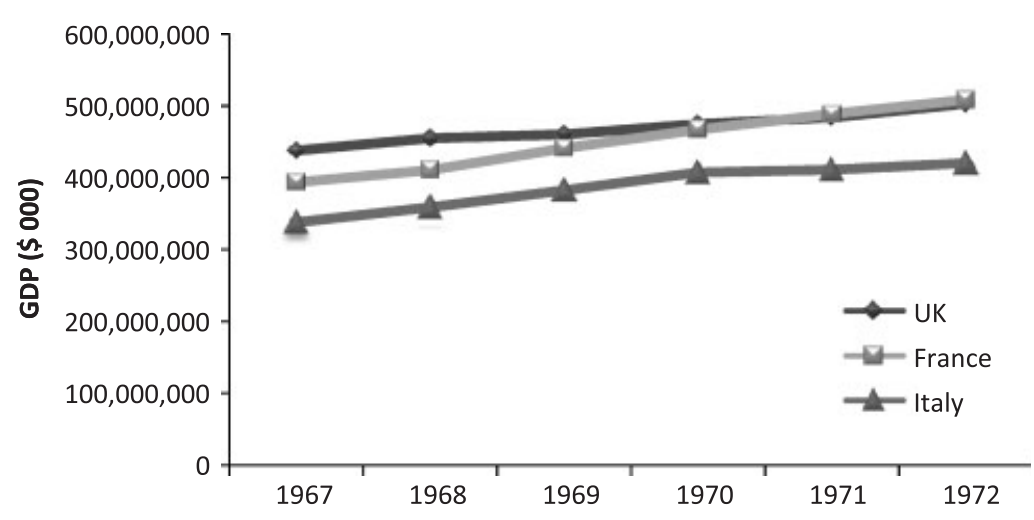

Figure 2. Annual GDP for 1967-1972 
savings. However, there is still some fall in consumption for two reasons. First, as we noted earlier, COMPACT assumes that a proportion of consumers are credit constrained, and so will not be able to borrow to cushion consumption. Second, higher interest rates designed to combat inflation lead consumers who are not credit constrained to shift some of their spending into the future, as the rewards from saving have increased.

Would our results be very different if we assumed more consumers were credit constrained? Some experiments suggest not, for the following reason. While raising the number of credit constrained consumers would mean more had to cut consumption when their income fell, there would be correspondingly fewer consumers who would be reducing consumption because interest rates were higher, and in COMPACT these two effects largely offset each other.

An important caveat, however, is that we assume a 'standard' response of the Bank of England to a rise in inflation, so that interest rates rise in an attempt to mitigate the impact of cost increases on inflation. In the circumstances of a pandemic it is possible that the Bank might well decide to ignore this inflation increase, and as a result the indirect declines in consumption, both immediately and in subsequent quarters, would be reduced. Investment begins to recover in the quarters after the pandemic (which reflects 'Tobin's q' theory of investment embodied in COMPACT). We assumed that there would be no net effect on government consumption as a result of the attack. This assumption is not critical. Even if we assumed that government consumption rose by $0.5 \%$ in the quarter of the attack, this would only add about $0.1 \%$ to GDP.

While an increase in the CFR and CAR has a notable effect on GDP and consumption in the shortterm, the long-term impacts are less significant, reflecting the contrast between the effect on health and that of the economy. However, if school closures were to last for the duration of the pandemic, inflation increases and long-term economic effects persist well beyond the end of the pandemic.

Clearly, these results are indicative rather than definitive. However, the analysis does suggest some general conclusions. First, the macroeconomic impact of a 'mild' outbreak is mainly felt through morbidity rather than mortality while, for the severe attack, the overall impact on annual GDP (a fall of around $1.55 \%$ ) is perhaps trivial compared with the mortality involved (300 000 deaths). Second, while absenteeism is limited to the peak of the pandemic, the macroeconomic impact is likely to be concentrated in the period of the attack and once the attack is over, the economy returns to approximately where it would have been if there had been no attack. Similar behaviour to this was observed for many sectors in the SARS outbreak of 2003 (Keogh-Brown and Smith, 2008).

While the disease impacts do not present a major cause of economic concern, the real economic danger occurs when policy and behavioural change in response to the pandemic occur. When absenteeism (through school closures) increases beyond a few weeks it causes inflation to rise during the pandemic, interest rates also rise, reducing consumption and investment, and these economic effects no longer rapidly disperse once the pandemic is over. Thus, the important consideration is the policy adopted in response to the pandemic at least as much, if not more, than the pandemic itself.

Precautionary changes in consumption patterns also present some alarming economic prospects. While the inflation effects are smaller to those of the high absenteeism scenarios, the GDP impacts are very large and both absenteeism and precautionary consumption shocks suggest historically unprecedented economic losses. While the size of these losses might promote some scepticism with regard to their validity, it may also be worth considering the differences between today's economic world and that of 1918. Today workers have much more scope to take days off work, and a much greater proportion of consumption is of items that have a high 'social' aspect and can therefore be easily postponed or abandoned. This means that modern economies may be much more vulnerable to sharp, but temporary, declines in activity than they were a century ago.

In order to illustrate these GDP impacts, it is helpful to bear in mind that in 2006 UK GDP per capita was $£ 21200$. Therefore, the economic impacts for the base scenario, high CFR, high CAR, and severe scenarios equate to per capita effects of $£ 47, £ 218, £ 226$ and $£ 329$, respectively, for the first year. 
To illustrate the impact of prophylactic absenteeism for 1 week and 4 weeks, the base cost to GDP per capita of $£ 47$ would increase to $£ 89$ and $£ 225$, respectively, while for 4 -week school closures the cost would be $£ 123$. Finally the cost to GDP per capita in the severe disease scenario would be $£ 437$, and if a quarter of school closure were combined with 4 weeks of prophylactic absenteeism were also included the cost would be £934. Impacts for the consumption shocks in terms of GDP per capita would be $£ 534$ for the base scenario and $£ 1283$ for the severe.

In an attempt to put these costs in context, it has been estimated that the discounted cost of a course of antivirals (including stockpiling over a 30 -year period, and administration) is approximately $£ 90$ (Siddiqui and Edmunds, 2008).

It is unknown whether the anticipated prophylactic absenteeism as recorded in (Sadique et al., 2007) will be realised, and the anticipated impact of school closures may be mitigated as working mothers may make alternative arrangements for care of their children, particularly if school closure is to last 13 weeks. However, the potential impact of these policies and practices is notable and may prove helpful in informing policy.

In terms of limitations and further research, the key assumption is that regarding the duration of absence from work. If an average of 3 weeks rather than 1 was assumed (CBO, 2005), the macroeconomic numbers would be scaled up by a substantial amount; although not by as much as three because the duration of school closure would not rise threefold. The effect of an increase in absenteeism is illustrated in the longer school closure scenarios. Further, COMPACT does not permit a detailed sectoral analysis of the potential impacts of pandemic influenza. Further research into the detailed impacts on the UK and other economies using a more sensitive model would be beneficial (Smith et al., 2005) and is currently being undertaken by the authors.

\section{ACKNOWLEDGEMENTS}

This work was done as part of 'SARSControl: effective and acceptable strategies for the control of SARS and new emerging infections in China and Europe', a European Commission project funded within the Sixth Framework Programme, Thematic Priority Scientific Support to Policies, Contract number: SP22-CT-2004-003824.

\section{REFERENCES}

Bartlett JG, Hayden FG. 2005. Influenza A (H5N1): will it be the next pandemic influenza? Are we ready? Annals of Internal Medicine 143(6): 460-462.

Beutels P, Edmunds W et al. 2008. Partially wrong? Partial equilibrium and the economic analysis of infectious disease emergencies of international concern. Health Economics 17(11): 1317-1322.

Beutels P, Jia N et al. 2009. The economic impact of severe acute respiratory syndrome (SARS) in Beijing, China. Tropical Medicine and International Health, DOI: 10.1111/j.1365-3156.2008.02210.x.

Blanke A, Sinclair T et al. 2001. The economy-wide effects of foot and mouth disease in the UK economy. Third Annual Conference European Trade Study Group, Brussels, Belgium.

Brainerd E, Siegler MV. 2003. The economic effects of the 1918 influenza epidemic. CEPR Discussion Papers 3791.

Brouwer W, Koopmanschap M. 2005. The friction-cost method: replacement for nothing and leisure for free? Pharmacoeconomics 23(2): 105-111.

CBO. 2005. A Potential Influenza Pandemic: Possible Macroeconomic Effects and Policy Issues. Congressional Budget Office.

Cooper BS, Pitman RJ et al. 2006. Delaying the international spread of pandemic influenza. PLoS Medicine 3(6): e212.

Cooper S, Coxe D. 2005. An Investors Guide to Avian Flu. BMO Nesbitt Burns Research. 
Darby J, Ireland J et al. 1999. Compact: a rational expectations, intertemporal model of the United Kingdom economy. Economic Modelling 16: 1-52.

Davis LE, Caldwell GG et al. 1970. Hong Kong influenza: the epidemiologic features of a high school family study analyzed and compared with a similar study during the 1957 Asian influenza epidemic 1970. American Journal of Epidemiology 92: 240-247.

Fan E. 2003. SARS: economic impacts and implications. Economics and Research Department Policy Brief 15, ADB.

Garner M, Fisher B et al. 2002. Economic aspects of foot and mouth disease: perspectives of a free country, Australia. Revue Scientifique et Technique 21: 625-635.

Garratt A, Lee K et al. 2003. A long run structural macroeconometric model of the UK. Economic Journal, Royal Economic Society 113(487): 412-455.

Garrett TA. 2008. War and pestilence as labor market shocks: U.S. manufacturing wage growth $1914-1919$. Economic Inquiry, DOI: 10.1111/j.1465-7295.2008.00137.x.

Holder A. 2004. The new Bank of England Quarterly Model. Bank of England Quarterly Bulletin, Summer.

Jacobs JPAM, Wallis KF. 2005. Comparing SVARS and SEMS: two models of the UK Economy. Journal of Applied Econometrics 20: 209-228.

James S, Sargent T. 2006. The Economic Effects of an Influenza Pandemic. Economic Analysis and Forecasting Division, Department of Finance, Canada, 9 May.

Jonung L, Roeger W. 2006. The macroeconomic effects of a pandemic in Europe - a model-based assessment. European Economy Economic Papers ISSN 1725-3187.

Keogh-Brown MR, Smith RD. 2008. The economic impact of SARS: how does the reality match the predictions? Health Policy 88: 110-120.

Knapp S, Rossi V et al. 2004. Assessing the Impact and Costs of Public Health Risks: the Example of SARS. Oxford Economic Forecasting Group.

Lee J, McKibbin WJ. 2003. Globalization and Disease: The Case of SARS. Economics RSPAS, Trade and Development.

Lucas R. 1976. Econometric Policy Evaluation: A Critique. Carnegie-Rochester Conference Series on Public Policy 1: 19-46.

McKibbin WJ, Sidorenko AA. 2006. Global Macroeconomic Consequences of Pandemic Influenza. Lowy Institute for International Policy.

Ministry of Health. 1920. Report on the Pandemic of Influenza, 1918-1919. His Majesty's Stationery Office.

Ministry of Health. 1960. The Influenza Epidemic in England and Wales, 1957-1958. Her Majesty's Stationery Office.

Postma MJ, Jansema P. 2005. Scenarios on costs and savings of influenza treatment and prevention for Dutch healthy working adults. Vaccine 23: 5365-5371.

Sadique M, Edmunds WJ et al. 2007. Precautionary behavior in response to perceived threat of pandemic influenza. Emerging Infectious Diseases 13(9): 1307-1313.

Sadique MZ, Adams EJ, Edmunds WJ. 2008. Estimating the costs of school closure for mitigating an influenza pandemic. BMC Public Health 8: 135.

Serfling RE. 1963. Methods for current statistical analysis of excess pneumonia influenza deaths. Public Health Reports 78: 494-506.

Siddiqui MR, Edmunds WJ. 2008. Cost-effectiveness of antiviral stockpiling and near-patient testing forpotential influenza pandemic. Emerging Infectious Diseases 14(2): 267-274.

Smith R, Yago M et al. 2005. Assessing the macroeconomic impact of a healthcare problem: the application of computable general equilibrium analysis to antimicrobial resistance. Journal of Health Economics 24: 1055-1075.

Smith RD. 2006. Responding to global infectious disease outbreaks: lessons from SARS on the role of risk perception, communication and management. Social Science and Medicine 63: 3113-3123.

Smith RD, Sommers T. 2003. Assessing the economic impact of public health emergencies of international concern: the case of SARS. Globalization. Trade and Health Working Papers Series, World Health Organization, Geneva.

Thompson D, Muriel P et al. 2002. Economic costs of a foot and mouth disease outbreak in the United Kingdom in 2001. Revue Scientifique et Technique de l office International des Epizooties 21(3): 675-687.

Woodall J, Rowse KEK. 1957. Age and Asian influenza. BMJ 29: 1316-1318.

Wren-Lewis S, Darby J et al. 1996. The macroeconomic effects of fiscal policy: linking an econometric model with theory. Economic Journal 106: 543-559. 